\title{
IL-10-Producing B Cells Suppress Effector T Cells Activation and Promote Regulatory $T$ Cells in Crystalline Silica-Induced Inflammatory Response In Vitro
}

\author{
Yiping Lu, ${ }^{1}$ Fangwei Liu, ${ }^{1}$ Chao Li, ${ }^{1}$ Ying Chen, ${ }^{1}$ Dong Weng, ${ }^{1,2}$ and Jie Chen ${ }^{1}$ \\ ${ }^{1}$ Division of Pneumoconiosis, School of Public Health, China Medical University, Shenyang, China \\ ${ }^{2}$ Department of Respiratory Medicine, Shanghai Pulmonary Hospital, Tongji University School of Medicine, Shanghai, China \\ Correspondence should be addressed to Jie Chen; jchen@cmu.edu.cn
}

Received 13 February 2017; Accepted 11 June 2017; Published 2 August 2017

Academic Editor: Alex Kleinjan

Copyright (c) 2017 Yiping Lu et al. This is an open access article distributed under the Creative Commons Attribution License, which permits unrestricted use, distribution, and reproduction in any medium, provided the original work is properly cited.

\begin{abstract}
Long-term exposure to crystalline silica leads to silicosis, which is characterized by persistent lung inflammation and lung fibrosis. Multiple immune cells have been demonstrated to participate in crystalline silica-induced immune responses. Our previous study indicated that B10 could control lung inflammation through modulating the Th balance in experimental silicosis in mice. However, the regulatory mechanism of $\mathrm{B} 10$ on $\mathrm{CD} 4^{+} \mathrm{T}$ cells is still unclear. MACS-sorted $\mathrm{CD} 19^{+} \mathrm{B}$ cells from the three different groups were cultured with $\mathrm{CD}^{+}{ }^{+} \mathrm{T}$ cells either with or without transwell insert plates to evaluate the effects of $\mathrm{B} 10$ on $\mathrm{CD} 4^{+} \mathrm{T}$ cells, including Teff and Treg. B10 was eliminated by anti-CD22 application in vivo. Flow cytometry was used to test the frequencies of CD ${ }^{+} \mathrm{T}$ cells, and the expressions of the related cytokines were detected by real-time PCR and CBA. Insufficient B10 elevated the levels of proinflammatory cytokines and promoted Th responses in a way independent upon cell-cell contact in the Teff and B cell coculture system. B10 could both increase Treg activity and enhance conversion of Teff into Treg. Our findings demonstrated that B10 could affect Th responses by the release of IL-10, enhancing Treg functions and converting Teff into Treg.
\end{abstract}

\section{Introduction}

Occupational exposure to particulates such as crystalline silica is a global cause of respiratory disease occurred in numerous industrial settings including mining, glass, drilling, and sawing [1]. Over the past decade, many efforts have been made to prevent the workers from exposure to crystalline silica; however, silicosis induced by crystalline silica exposure is still a global heavy burden [2-4]. Inhalation of crystalline silica leads to activation and recruitment of lymphocytes, resulting in lung inflammation and fibrosis $[5,6]$. On account of impaired particle clearance, silicosis is irreversible and incurable, leading to sustaining lung inflammation [7]. Therefore, to explore its pathogenesis and regulatory mechanism is particularly important for effective treatment of silicosis.

Crystalline silica is first recognized by macrophages, and then T cells and $\mathrm{B}$ cells can be activated $[8,9]$. In the past, $\mathrm{B}$ cells are known to produce antibodies and proinflammatory cytokines and present antigens to activate $\mathrm{T}$ cell-mediated immune responses [10]. However, a novel subset of $B$ cells, regulatory B cells (Breg), has been found [11]. Breg exerts immunosuppressive functions in tumor, autoimmunity, infections, and inflammation [12-15]. Although the specific phenotypes of Breg are varied in different diseases, the secretion of IL-10 is a unique feature of Breg [16-19]. As a result, $\mathrm{CD} 19^{+} \mathrm{IL}-10^{+}$Breg is also known as IL-10-producing B cells (B10) [20]. Much attention has been paid to the role of Breg on $\mathrm{T}$ cells. Researchers found that Breg could reduce Th1/ Th17 responses and induce Treg [21-24].

Our previous studies demonstrated that $\mathrm{CD}^{+} \mathrm{T}$ helper (Th) cells played a crucial role in immune response in silicosis. $\mathrm{CD} 4^{+} \mathrm{CD} 25^{-}$effector T cells (Teff), such as Th1, Th2, and Th17, took part in different stages of silicosis according to the murine studies [25-27]. $\mathrm{CD}^{+} \mathrm{CD} 25^{+}$regulatory $\mathrm{T}$ cells (Treg) were inducible and made efforts to modulate the Th responses after crystalline silica exposure [28-30]. The immune homeostasis and the balance among different Th 
responses determined the progress of silicosis. We also found that B10 could modulate the progress of crystalline silicainduced lung inflammation and fibrosis by suppressing the Th1 response and promoting Treg function in mice, which was consistent with previous studies [31]. However, the actual role of $\mathrm{B} 10$ on $\mathrm{CD}^{+} \mathrm{T}$ cells in silicosis still needs further exploration.

To study the modulatory function of B10 on Teff and Treg, respectively, we designed a series of studies in vitro. Anti-CD22 mAb, which was reported to eliminate B10, was used to restrict the expansion of crystalline silica-induced B10 [31-33]. Crystalline silica particle was used to trigger the B10 expansion in mice. $\mathrm{CD} 19^{+} \mathrm{B}$ cells, $\mathrm{CD} 4^{+} \mathrm{CD} 25^{-}$Teff, and $\mathrm{CD} 4^{+} \mathrm{CD} 25^{+}$Treg were isolated from different groups of mice. A CD $19^{+} \mathrm{B}$ cell and Teff/Treg coculture system was set up in vitro. Our study demonstrated that B10 could suppress the levels of crystalline silica-activated proinflammatory cytokines in cocultured system in vitro. The suppressive function of $\mathrm{B} 10$ on Th responses was independent upon cell-cell contact. B10 could both affect Treg and promote the conversion of $\mathrm{CD} 4^{+} \mathrm{CD} 25^{-}$Teff into Treg, which could subsequently suppress the Th responses.

\section{Materials and Methods}

2.1. Animals. Female C57BL/6 mice were purchased from SLAC Laboratory Animal Co. Ltd. (Shanghai, China) at 6-8 weeks of age. All mice were maintained in a specific pathogen-free conditions and fed on a standard mouse chow at an environmental temperature of $24 \pm 1^{\circ} \mathrm{C}$ and a $12 \mathrm{~h} / 12 \mathrm{~h}$ light/dark cycle with water available ad libitum. The animal study was approved by the Animal Care and Use Committee of China Medical University (CMU62043018), which complies with the National Institutes of Health Guide for the Care and Use of Laboratory Animals. The study was performed in accordance with the approved guidelines.

2.2. Crystalline Silica Exposure and B10 Depletion. Natural crystalline silica particles (Min-U-Sil 5 ground silica; size distribution: $97 \%<5 \mu \mathrm{m}$ diameter, $80 \%<3 \mu \mathrm{m}$ diameter; median diameter $1.4 \mu \mathrm{m}$ ) were obtained from the U.S. Silica Company (Frederick, MD). Crystalline silica particles were boiled in $1 \mathrm{~N} \mathrm{HCl}$ to remove endotoxins. Before use, the suspension was autoclaved and then sonicated.

Mice were randomly distributed into three groups: the control group, the silica group, and the silica\&antiCD22 group, containing fifteen animals each. All mice were anesthetized with intraperitoneal injection of $2 \%$ pentobarbital sodium ( $45 \mathrm{mg} / \mathrm{kg}$ body weight). The silica group and the silica\&anti-CD22 group mice received $3 \mathrm{mg} / 50 \mu \mathrm{l}$ crystalline silica suspension intratracheally to induce experimental silicosis. The control group mice received $50 \mu \mathrm{l}$ sterile saline.

For continuing depletion of $\mathrm{CD}_{1} 9^{+} \mathrm{IL}-10^{+}$regulatory $\mathrm{B}$ cell, the silica\&anti-CD22 group mice received $300 \mu \mathrm{g}$ antiCD22 mAb (KH2014176, F239, Sangon Biotech, Shanghai, China) one day before the crystalline silica exposure and six days after crystalline silica exposure, respectively. All mice were sacrificed seven days postexposure to crystalline silica.
2.3. Cell Coculture. $\mathrm{CD} 19^{+} \mathrm{B}$ cells were immediately isolated from the three groups after the mice were sacrificed by using magnetic-activated cell sorting (MACS) technology (Miltenyi Biotech, Auburn, CA). CD ${ }^{+}$T cells were first purified from control group mouse spleen by MACS, and then $\mathrm{CD} 4{ }^{+} \mathrm{CD} 25^{+}$Treg and $\mathrm{CD} 4{ }^{+} \mathrm{CD} 25^{-}$Teff were separately isolated by positive selection and negative selection according to a magnetic column-based system Treg/Teff cell isolation kit (Miltenyi Biotech, Auburn, CA).

$\mathrm{CD} 4^{+} \mathrm{CD} 25^{+} \mathrm{T}$ cells $\left(1 \times 10^{5}\right)$ or $\mathrm{CD} 4^{+} \mathrm{CD} 25^{-} \mathrm{T}$ cells $\left(1 \times 10^{6}\right)$ were cultured with $\mathrm{CD} 19^{+} \mathrm{B}$ cells $\left(1 \times 10^{6}\right)$ from three different group of mice separately for $72 \mathrm{~h}$ in complete RPMI 1640 medium containing 10\% FBS (Biological Industries, Kibbutz Beit-Haemek, Israel), 1\% HEPES (SigmaAldrich), $100 \mathrm{U}$ penicillin-streptomycin (Invitrogen), and $1 \mu \mathrm{g} / \mathrm{ml}$ anti-CD3/CD28 monoclonal antibodies at $37^{\circ} \mathrm{C}$ in $5 \% \mathrm{CO}_{2}$. To block the cell-cell contact, transwell insert (0.4 $\mu \mathrm{m}$ pore size; Costar; Corning; USA) was used during cell culture. $\mathrm{CD} 19^{+} \mathrm{B}$ cells were placed in the lower chamber, and Treg/Teff were in the upper chamber.

2.4. Flow Cytometry. For B cell staining, PerCP-Cy5.5-conjugated CD19 (BD Pharmingen) and PE-conjugated anti-IL-10 (BD Pharmingen) mAbs were used. For identification of $\mathrm{T}$ cells, PerCP-Cy5.5-conjugated CD4 (BD Pharmingen), PEconjugated CD25 (Miltenyi Biotech, Auburn, CA), Alexa Fluor 488-conjugated anti-IFN- $\gamma$ (BD Pharmingen), PEconjugated anti-IL-17A (BD Pharmingen), and Alexa Fluor 647-conjugated anti-Foxp3 (BD Pharmingen) were used. Cells from purified $B$ cells of three different groups or the cocultured cells were stimulated with a leukocyte activation cocktail (BD Pharmingen, San Jose, CA, USA) for $5 \mathrm{~h}$, followed by blocking with purified rat anti-mouse CD16/32 (BD Pharmingen) for $10 \mathrm{mins}$ at $4^{\circ} \mathrm{C}$. For surface staining, cells were stained with CD19-PerCP-Cy5.5, CD-25-PE, or CD4-PerCP-Cy5.5 mAbs. Cells were washed, fixed, permeabilized, and stained for detection of intracellular cytokines or transcription factors with IL-10-PE, IFN- $\boldsymbol{\gamma}$-Alexa Fluor 488, IL-17A-PE, or Foxp3-Alexa Fluor 647 mAbs. Cells were subsequently analyzed using a FACSCanto II flow cytometer (BD Biosciences, Franklin Lakes, NJ). Dead cells and crystalline silica particles were gated out according to forward scattering (FSC) and side scattering (SSC). Cells were analyzed with FlowJo Software (TreeStar).

2.5. RNA Extraction and Real-Time PCR. Total RNA was extracted from cocultured cells using TRIzol reagent (Invitrogen, Carlsbad, CA, USA), according to the manufacturer's protocol. The RNA concentration and the A260/A280 ratio were determined using a UV spectrophotometer.

Primers were designed with Primer3 (http://bioinfo.ut. ee/primer3-0.4.0/primer3/), and the sequences were checked by performing a BLAST search (http://blast.ncbi.nlm.nih. gov/Blast.cgi) (Table 1). In general, $2 \mu \mathrm{g}$ total RNA was reverse transcribed in a $20 \mu \mathrm{l}$ reaction using the following programs: $37^{\circ} \mathrm{C}$ for $15 \mathrm{~min}$ and $85^{\circ} \mathrm{C}$ for $5 \mathrm{~s}$ using PrimeScript RT kit (DRR047A, Takara, Japan). Then, $1 \mu \mathrm{l}$ of cDNA was used for real-time PCR analysis in a $13 \mu \mathrm{l}$ reaction volume using Premix Ex Taq II RT-PCR kit (DRR081A; Takara). 
Table 1: Primer sequences for real-time PCR.

\begin{tabular}{|c|c|c|}
\hline Mus musculus gene name & Forward $5^{\prime}-3^{\prime}$ & Reverse $5^{\prime}-3^{\prime}$ \\
\hline T-box 21 & TCAACCAGCACCAGACAGAGA & TCCACCAAGACCACATCCAC \\
\hline Interferon gamma & AAGCGTCATTGAATCACACCTG & TGACCTCAAACTTGGCAATACTC \\
\hline GATA binding protein 3 & GGATGTAAGTCGAGGCCCAAG & ATTGCAAAGGTAGTGCCCGGTA \\
\hline Interleukin 4 & ACGGAGATGGATGTGCCAAAC & AGCACCTTGGAAGCCCTACAGA \\
\hline Interleukin 13 & CCCCTGTGCAACGGCAGCAT & GAAGGGGCCGTGGCGAAACA \\
\hline Tumor necrosis factor- $\alpha$ & ACTCCAGGCGGTGCCTATGT & GTGAGGGTCTGGGCCATAGAA \\
\hline Interleukin 6 & CAACGATGATGCACTTGCAGA & CTCCAGGTAGCTATGGTACTCCAGA \\
\hline RAR-related orphan receptor gamma & ACGGCCCTGGTTCTCATCA & CCAAATTGTATTGCAGATGTTCCAC \\
\hline Interleukin $17 \mathrm{~A}$ & GCAAAAGTGAGCTCCAGAAGG & TCTTCATTGCGGTGGAGAGTC \\
\hline Interleukin 23 & ACATGCACCAGCGGGACATA & CTTTGAAGATGTCAGAGTCAAGCAG \\
\hline Forkhead box P3 & CCCATCCCCAGGAGTCTTG & ACCATGACTAGGGGCACTGTA \\
\hline Interleukin 10 & GGGGCCAGTACAGCCGGGAA & CTGGCTGAAGGCAGTCCGCA \\
\hline Transforming growth factor beta 1 & TGTGGAACTCTACCAGAAATATAGC & GAAAGCCCTGTATTCCGTCTC \\
\hline Glyceraldehyde-3-phosphate dehydrogenase & CAATGTGTCCGTCGTGGATCT & GTCCTCAGTGTAGCCCAAGATG \\
\hline
\end{tabular}

Amplification efficiency differences between target genes and housekeeping genes were identified by comparing the slopes of the standard curves. The PCR reactions were run on an ABI 7500 cycler (Applied Biosystems) using the following programs: $95^{\circ} \mathrm{C}$ for $30 \mathrm{~s}, 40$ cycles of $95^{\circ} \mathrm{C}$ for $5 \mathrm{~s}$, and $60^{\circ} \mathrm{C}$ for $34 \mathrm{~s}$. Analyses were performed using the 7500 system software (Applied Biosystems).

2.6. Cytokine Analysis. Secreted protein levels in the supernatant of cocultured system were examined by CBA assay using mouse Th1/Th2/Th17 cytokine kit (BD Pharmingen) following the manufacturer's instructions. Generally, multiple capture beads were mixed together, including TNF- $\alpha$, IL-6, IFN- $\gamma$, IL-2, IL-17, and IL-10. The mixed capture beads were cocultured with $50 \mu \mathrm{l}$ supernatant and detection reagent for $2 \mathrm{~h}$. Beads were washed carefully and resuspended. Samples were analyzed using a FACSCanto II system (BD Biosciences). Data was analyzed with FCAP Array software.

2.7. Statistics. Values for all measurements were expressed as the mean \pm SEM. Data was analyzed for significance in SPSS software, version 19.0 (SPSS Inc., Chicago, IL, USA) by one-way ANOVA with Student-Newman-Keuls test as specified. All experiments were repeated at least once with consistent results. $P<0.05$ was considered statistically significant.

\section{Results}

3.1. B10 Insufficiency Elevated the Levels of Proinflammatory Cytokines in the Teff and B Cell Coculture System In Vitro. CD $19^{+}$B cells were purified from mouse spleens in different groups using MACS kits as described in the Materials and Methods section. Control B referred to B cells sorted from the control group mice; silica B referred to B cells isolated from the silica group mice; and silica\&anti-CD22 B referred to $B$ cells purified from the silica\&anti-CD22 group mice treated with anti-CD22 mAb which were also exposed to crystalline silica particles. The purification of $\mathrm{CD} 19^{+} \mathrm{B}$ cell was more than $90 \%$ after MACS sorting (Figure 1(a1)). The percentage of B10 in the silica B was obviously higher than that in the control B. Cells from the silica\&antiCD22 B contained less B10 compared with those from the silica $B$, which was consistent with our previous report [31]. And this difference among the three groups kept significant even after $72 \mathrm{~h}$ culture (Figure 1(a2)). Flow cytometry analyses showed the percentages of CD $19^{+} \mathrm{IL}-10^{+} \mathrm{B} 10$ in different groups (Figure 1(a3)).

Purified control B, silica B, or silica\&anti-CD22 B cells were separately cocultured with sorted $\mathrm{CD} 4^{+} \mathrm{CD} 25^{-}$Teff cells for $72 \mathrm{~h}$ (Figures 1(b1) and 1(b2)). To check the potential role of B10 in modulating inflammatory response, two characterized proinflammatory cytokines TNF- $\alpha$ and IL- 6 were tested by real-time PCR and CBA. The expressions of TNF- $\alpha$ and IL-6 in the silica\&anti-CD22 B + Teff group were higher than those in the silica $\mathrm{B}+$ Teff group (Figures $1(\mathrm{~d})$ and 1(e)). And this difference was confirmed by CBA, which indicated that insufficient B10 led to elevations of inflammatory cytokines (Figures $1(\mathrm{f})$ and $1(\mathrm{~h})$ ). Then, purified $\mathrm{B}$ cells from different groups were cocultured separately with sorted $\mathrm{CD} 4{ }^{+} \mathrm{CD} 25^{-}$Teff cells for $72 \mathrm{~h}$ with insert plates (Figure 1(c)). The levels of TNF- $\alpha$ and IL-6 in culture supernatant of the silica\&anti-CD22 B + Teff group also increased compared with the silica B + Teff group (Figures 1(d), 1(e), $1(\mathrm{f}), 1(\mathrm{~g}), 1(\mathrm{~h})$, and $1(\mathrm{i}))$, which indicated that the role of B10 on inflammatory cytokines was not dependent upon cell-cell contact.

3.2. Insufficient B10 Aggravated Th Responses in a Way Independent upon Cell-Cell Contact. Multiple Th responses were reported to be involved in crystalline silica-induced lung inflammation in mice. So, we wondered that whether B10 directly affected Th responses in vitro. Flow cytometry analyses showed that the percentage of CD $4^{+}$IFN- $\gamma^{+}$(Th1) cells in the silica\&anti-CD22 B + Teff group increased significantly compared with that in the silica B+Teff group (Figures 2(a1) and 2(a2)). The typical Th1 cytokine, IFN- $\gamma$ 


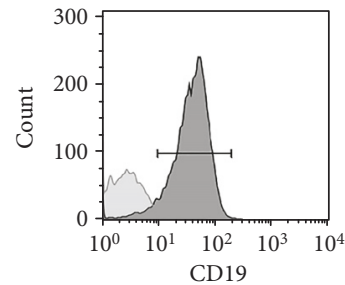

(a1)

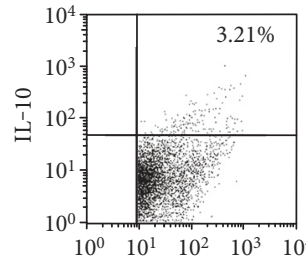

(1)

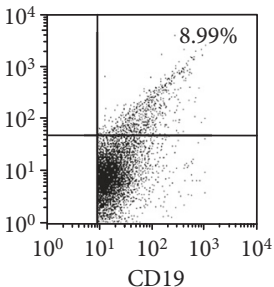

CD19
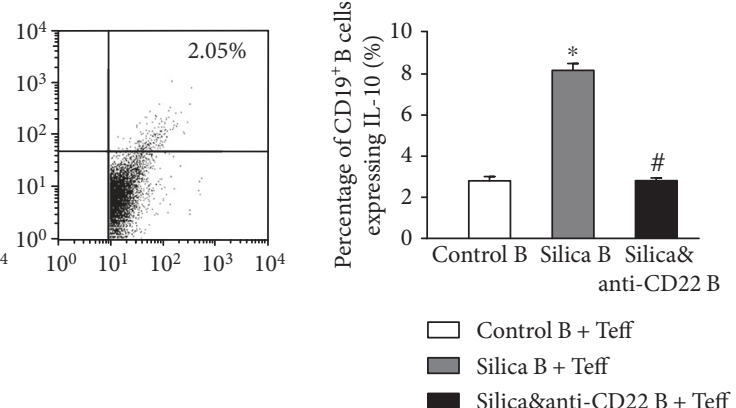

(a3)

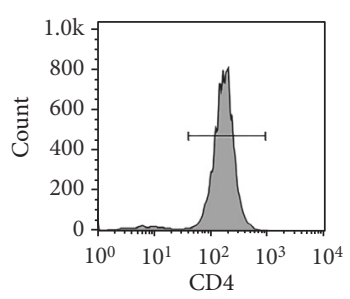

(b1)

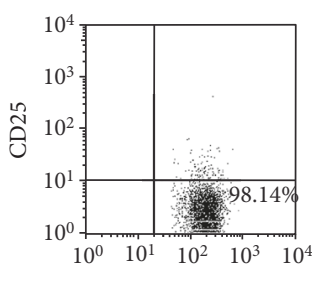

(b2) (a2)
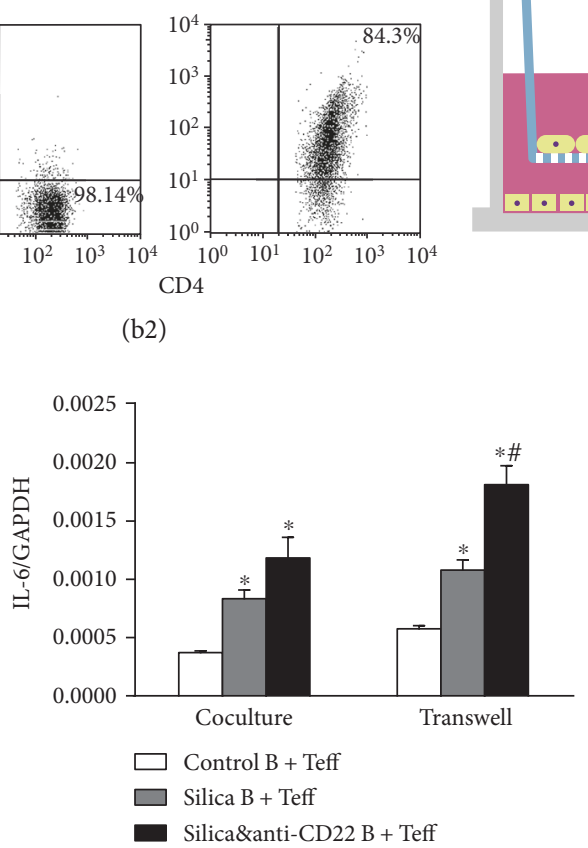

(e)

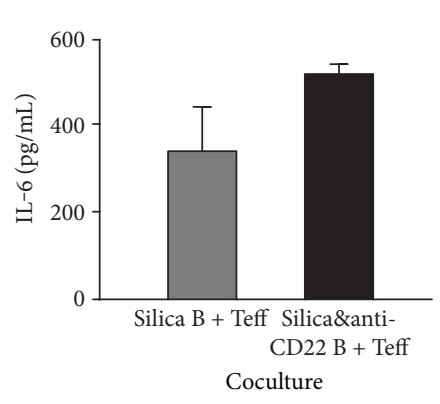

(h)

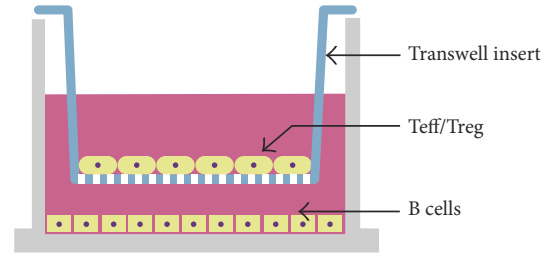

(c)

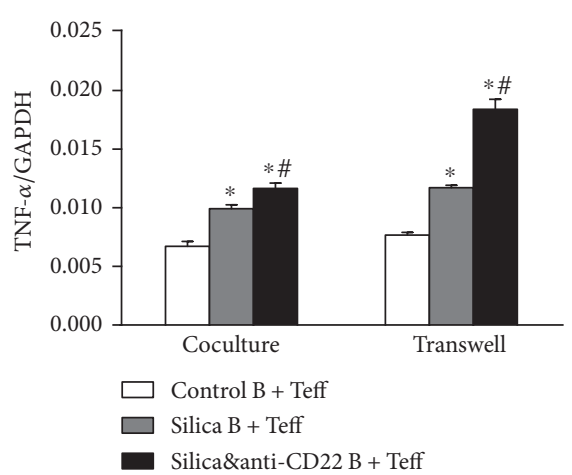

(d)

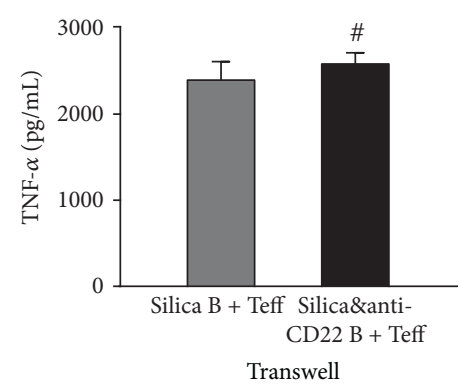

(g)

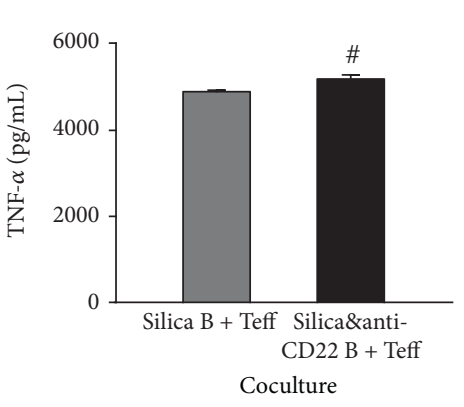

(f)

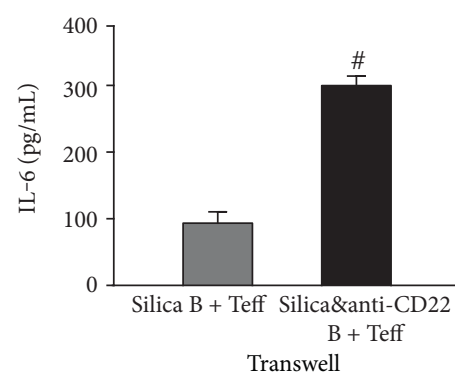

(i)

FIGURE 1: Insufficient B10 promoted the proinflammatory cytokines in the Teff and B cell coculture system in vitro. (a1) CD19 ${ }^{+}$B cells were purified and checked by flow cytometry. (a2, a3) The percentages of B10 in different groups were tested by flow cytometry. (b1, b2) The $\mathrm{CD} 4{ }^{+} \mathrm{CD} 25^{-}$Teff and $\mathrm{CD} 4{ }^{+} \mathrm{CD} 25^{+}$Treg were purified and checked by flow cytometry. (c) A schematic of B cell and Teff coculture system with insert plates in vitro. (d, e) The expressions of TNF- $\alpha$ and IL-6 in different groups of the B cell and Teff coculture system with or without insert plates were assayed by real-time PCR. ( $f, h$ ) The secretions of TNF- $\alpha$ and IL-6 in supernatant of the B cell and Teff coculture system were assayed by CBA. (g, i) The concentrations of TNF- $\alpha$ and IL- 6 in supernatant of the B cell and Teff coculture system with insert plates were assayed by CBA. (Data was presented as mean $\pm \operatorname{SEM}(n=5) .{ }^{*} p<0.05$, significantly different compared with the control B + Teff group. ${ }^{*} p<0.05$, significantly different compared with the silica B + Teff group.)

$[34,35]$, was examined by real-time PCR and CBA. The expression and secretion of IFN $-\gamma$ in the silica\&anti-CD22 $\mathrm{B}+$ Teff group added dramatically compared with those in the silica B + Teff group (Figures 2(b) and 2(d)). Although the difference of Th1 transcript factor (T-bet) [35] between the silica\&anti-CD22 B + Teff group and the silica 

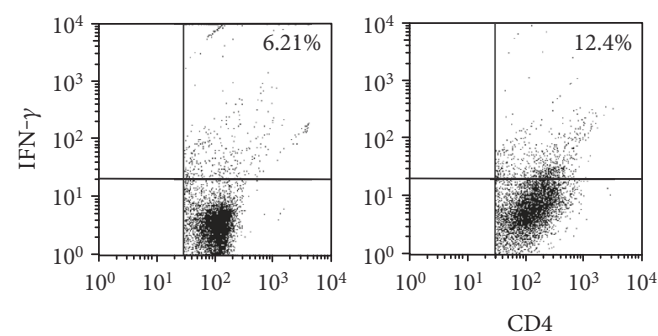

(a1)

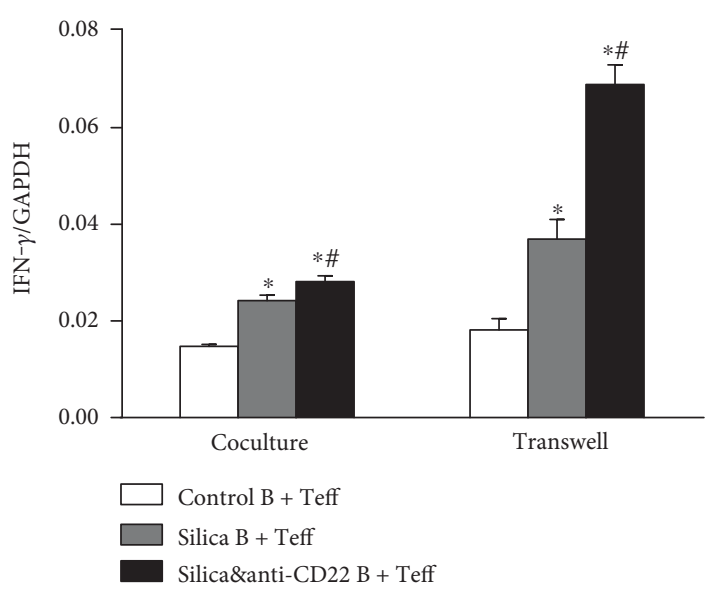

(b)

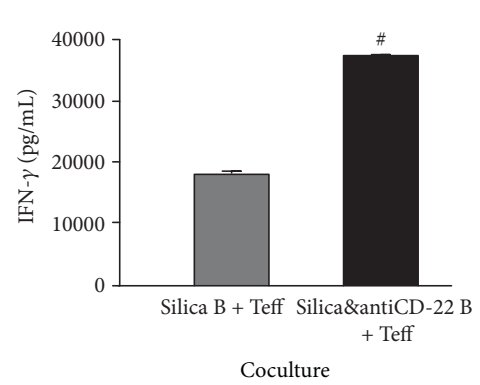

(d)
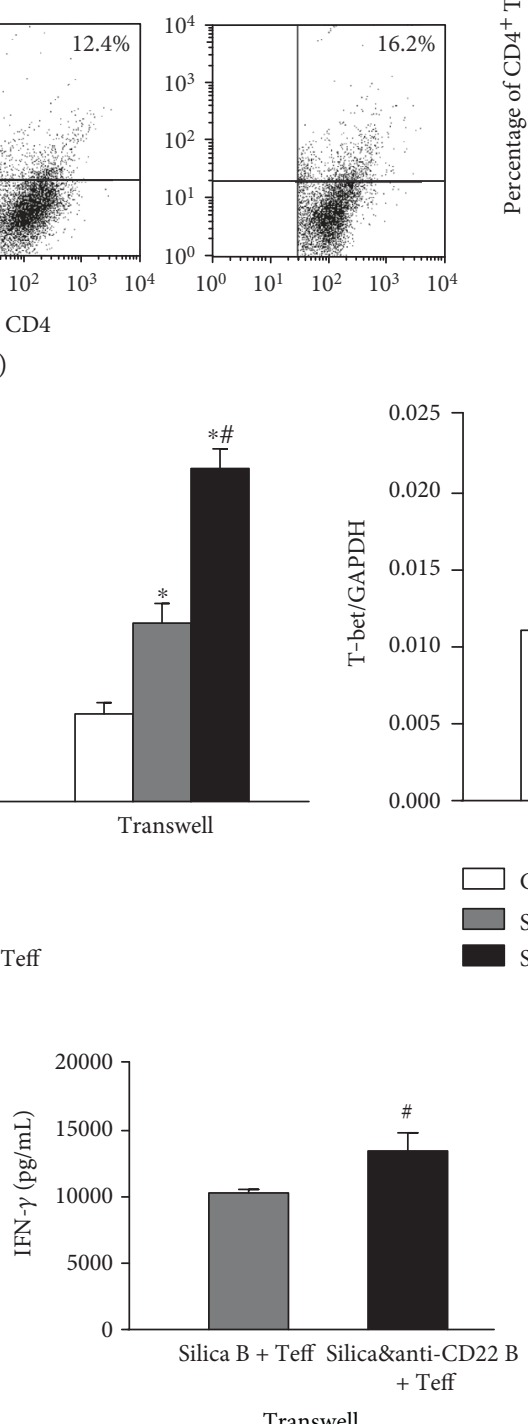

(e)

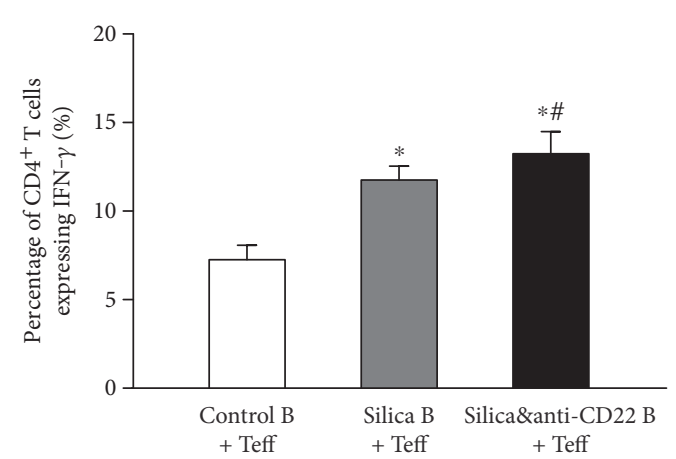

(a2)

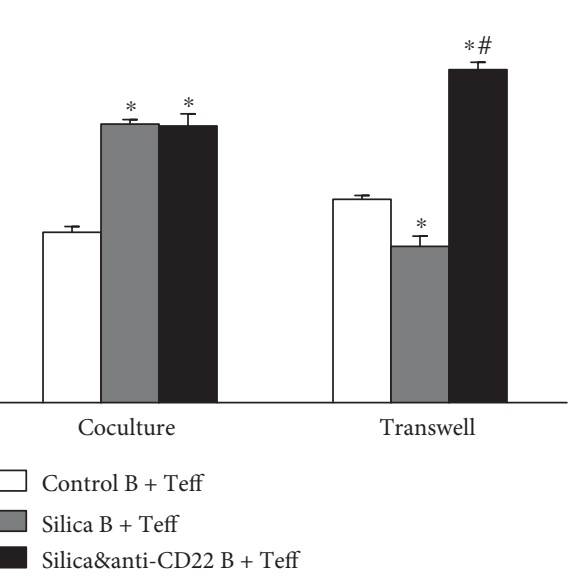

(c)

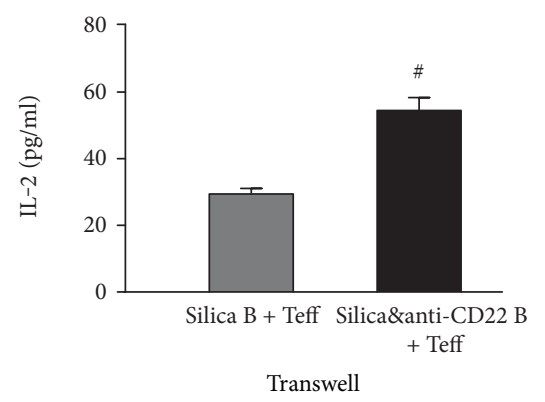

(f)

Figure 2: Insufficient B10 aggravated the Th1 response in the Teff and B cell coculture system in vitro. (a1, a2) The percentages of $\mathrm{CD} 4^{+}$IFN $-\gamma^{+}$Th1 cells in different groups of the B cell and Teff coculture system were studied by flow cytometry. (b, c) The expressions of IFN- $\gamma$ and T-bet in different groups of the B cell and Teff coculture system with or without insert plates were assayed by real-time PCR. (d) The secretions of IFN- $\gamma$ in supernatant of the B cell and Teff coculture system were assayed by CBA. (e, f) The concentrations of IFN- $\gamma$ and IL-2 in supernatant of the B cell and Teff coculture system with insert plates were assayed by CBA. (Data was presented as mean \pm SEM $(n=5) .{ }^{*} p<0.05$, significantly different compared with the control $\mathrm{B}+$ Teff group. $\# p<0.05$, significantly different compared with the silica $B+$ Teff group.)

$\mathrm{B}+$ Teff group was not significant, Th1 response might be affected by insufficient B10 (Figure 2(c)). The enhanced Th1 response was even notable when coculturing B cells and Teff with insert plates. The elevated level of IFN- $\gamma$ in the silica\&anti-CD22 B + Teff group was still significant (Figures 2(b) and 2(e)). The expressions of T-bet and the secretion of IL-2 in the silica\&anti-CD22 $\mathrm{B}+$ Teff group also enlarged much more than those of the silica $B+$ Teff group (Figures 2(c) and 2(f)).
Besides, Th2 response was also reported to play a crucial role in the development of silicosis. In this study, typical Th2 cytokines IL-4 and IL-13 and the Th2 transcript factor (GATA3) [36] were examined in the cocultured system in vitro (Figures 3(a), 3(b), and 3(c)). The expressions of IL-4 and IL-13 both elevated prominently in the silica\&antiCD22 B + Teff group compared with those in the silica $\mathrm{B}+$ Teff group (Figures $3(\mathrm{a})$ and $3(\mathrm{~b})$ ). Meanwhile, the increased GATA3 expression clarified the promoted Th2 


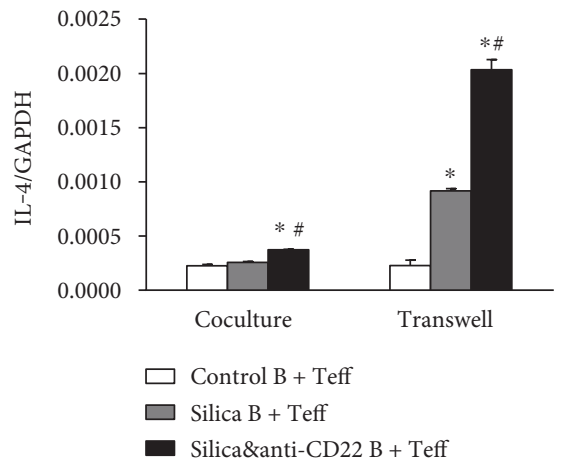

(a)
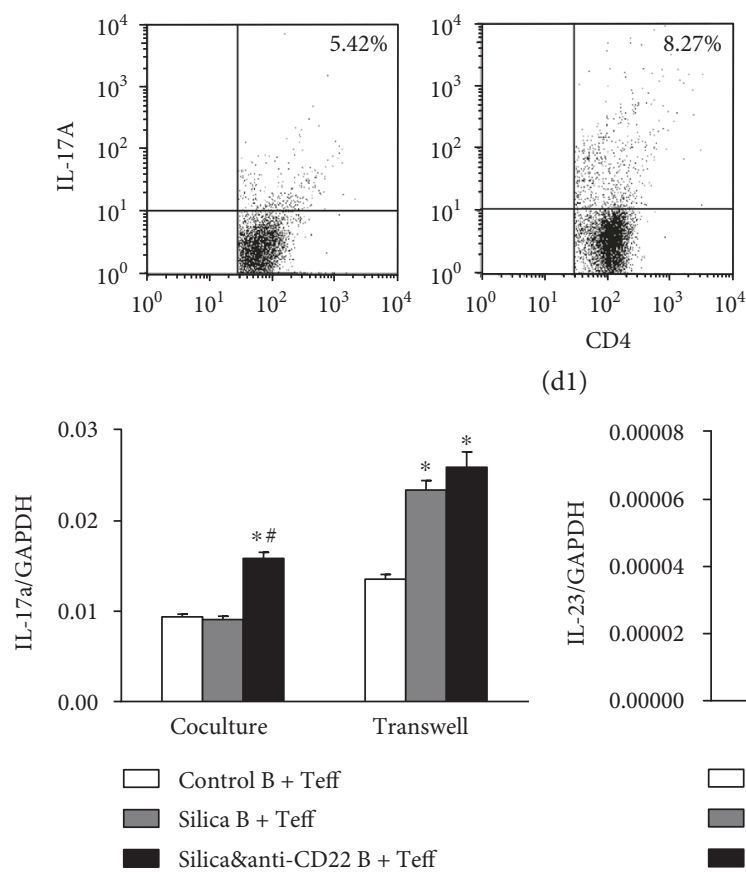

(e) (d1)

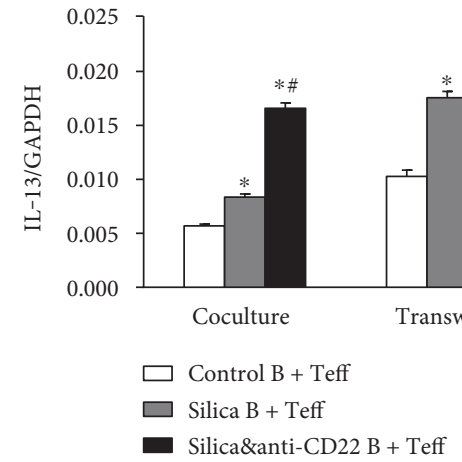

(b)
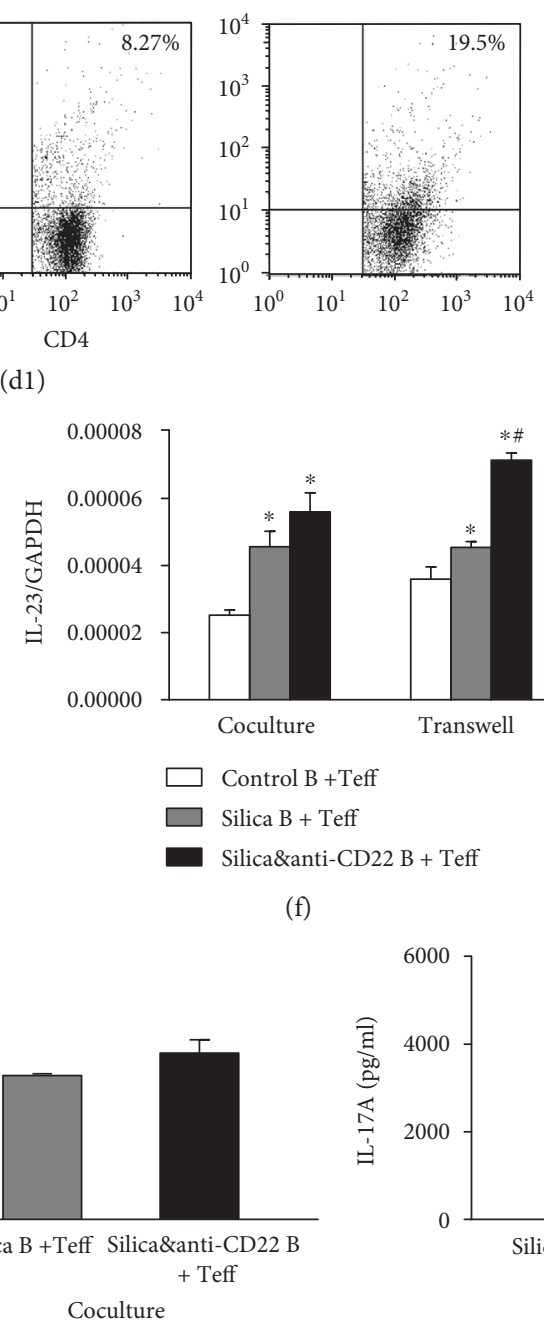

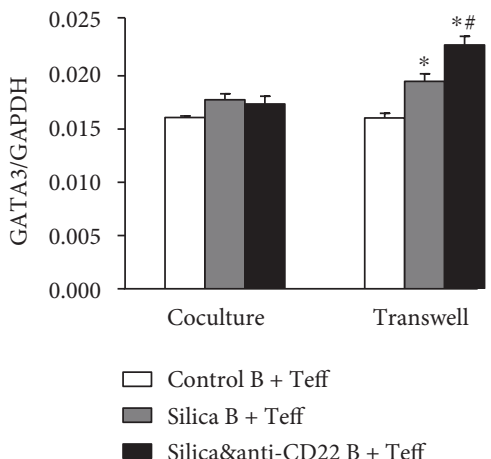

(c)

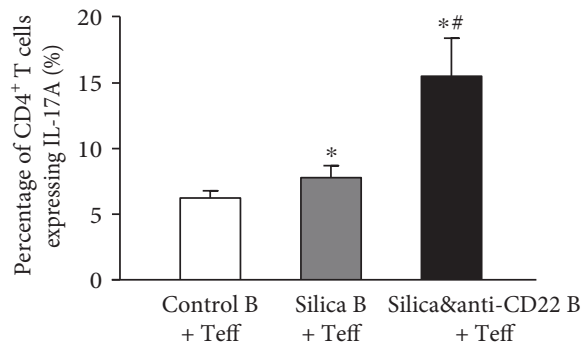

(d2)

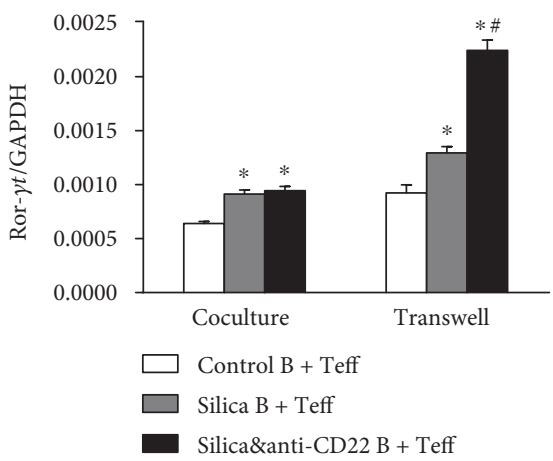

(g) (h)

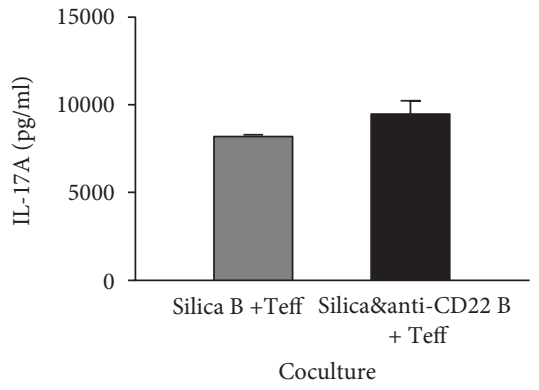

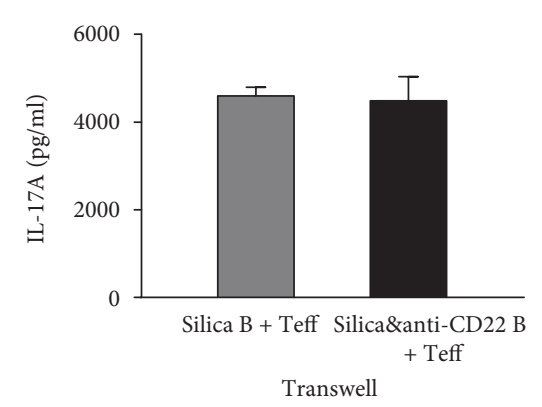

(i)

Figure 3: Insufficient B10 promoted the Th2/Th17 responses in the Teff and B coculture system in vitro. (a, b, c) The expressions of IL-4, IL-13, and GATA3 in different groups of the B cell and Teff coculture system with or without insert plates were assayed by real-time PCR. (d1, d2) The percentages of $\mathrm{CD}^{+}$IL-17A ${ }^{+}$Th17 cells in different groups of the B cell and Teff coculture system were studied by flow cytometry. (e, f, g) The expressions of IL-17A, IL-23, and ROR- $\gamma$ t in different groups of the B cell and Teff coculture system with or without insert plates were assayed by real-time PCR. (h, i) The secretions of IL-17A in supernatant of the B cell and Teff coculture system with or without insert plates were assayed by CBA. (Data was presented as mean \pm SEM $(n=5)$. ${ }^{*} p<0.05$, significantly different compared with the control $\mathrm{B}+$ Teff group. ${ }^{\#} p<0.05$, significantly different compared with the silica $\mathrm{B}+$ Teff group.) 
response as supplement (Figure 3(c)). The effect on Th2 response was not dependent upon cell-cell contact, since the elevated levels of Th2 cytokines and Th2 transcript factor were still significant when coculturing B cells and Teff with insert plates (Figures 3(a), 3(b), and 3(c)).

Another indispensable Th response, Th17, was also demonstrated to be affected by insufficient B10 according to our results. The percentage of $\mathrm{CD}^{+} \mathrm{IL}^{-17^{+}}$(Th17) cells in the silica\&anti-CD22 B + Teff group was markedly higher than that of the silica $\mathrm{B}+$ Teff group according to flow cytometry (Figures $3(\mathrm{~d} 1)$ and $3(\mathrm{~d} 2)$ ). The expression and secretion of IL-17A elevated more in the silica\&anti-CD22 B + Teff group compared with those in the silica B + Teff group (Figures 3(e) and $3(\mathrm{~h}))$. IL-23 in the silica\&anti-CD22 B + Teff group, which had a positive role in promoting the differentiation of Th17 cells, also expressed more than that in the silica $\mathrm{B}+$ Teff group (Figure 3(f)). Next, different groups of B cells and Teff were cocultured with insert plates. Although the difference of IL-17A level between the silica B+Teff group and the silica\&anti-CD22 B + Teff group was not significant statistically, the expressions of IL-23 and ROR $\gamma t$ increased dramatically in the silica\&anti-CD22 B+Teff group (Figures 3(f) and 3(g)).

3.3. B10 Could Enhance Treg Response and Convert Teff into Treg. $\mathrm{CD} 4^{+} \mathrm{CD} 25^{+}$Treg was claimed to have a crucial role in regulating silicosis development and the crystalline silicainduced Th immune response according to our previous study $[28,29]$. We firstly cocultured the CD $19^{+} \mathrm{B}$ cells and $\mathrm{CD} 4^{+} \mathrm{CD} 25^{+}$Treg this time and checked if the change of B10 could influence Treg in vitro. Flow cytometry showed that the percentage of $\mathrm{CD}^{+}{ }^{+}$Foxp $3^{+}$Treg increased obviously in the silica B+Treg group (Figures 4(a1) and 4(a2)). According to real-time PCR assay, the expression of Treg transcript factor (Foxp3) was also suppressed in the silica\&anti-CD22 B + Treg group compared with the silica $\mathrm{B}+$ Treg group (Figure 4(b)). The expression of Treg functional molecule CTLA4 and the inhibitory cytokine IL-10 also demonstrated the similar trend as Foxp3 (Figures 4(c) and 4(d)). However, the change in another inhibitory cytokine TGF- $\beta$ was not obvious among those groups (Figure 4(e)).

As known, $\mathrm{CD} 4^{+} \mathrm{CD} 25^{-}$Teff could be converted into Treg under some circumstances $[24,37,38]$. So, we next detected Treg and its related molecules in the $\mathrm{CD}_{19^{+}} \mathrm{B}$ cell and $\mathrm{CD} 4^{+} \mathrm{CD} 25^{-}$Teff coculture system. The percentage of $\mathrm{CD} 4^{+} \mathrm{Foxp}^{+}$Treg also enhanced in the silica B + Teff group, which indicated that crystalline silica instillation in mice not only influenced the Treg itself but also promoted the Treg differentiation from Teff. And this differentiation was affected by insufficient B10 based on the fact that the percentage of $\mathrm{CD} 4{ }^{+}$Foxp $3^{+}$Treg was restrained in the silica\&anti-CD22 $\mathrm{B}+$ Teff group (Figures 4(f1) and 4(f2)). The real-time PCR assay on Foxp3 and CTLA4 also supported the demonstration (Figures $4(\mathrm{~g})$ and $4(\mathrm{~h})$ ). The situation was also checked in the $\mathrm{CD} 19^{+} \mathrm{B}$ cell and $\mathrm{CD} 4^{+} \mathrm{CD} 25^{-}$Teff coculture system with insert plates. And the trend among different groups was not changed when the cell-cell contact was blocked by insert plates (Figures $4(\mathrm{~g})$ and $4(\mathrm{~h})$ ).
The difference of the expression of TGF- $\beta$ between the silica B+Teff group and the silica\&anti-CD22 B+Teff group was not significant in the cocultured system either with or without insert plates (Figure 4(i)). On the other hand, the expression and secretion of IL-10 dramatically decreased in the silica\&anti-CD22 B+Teff group compared with those in the silica $\mathrm{B}+$ Teff group (Figures $4(\mathrm{j}$ ) and $4(\mathrm{k}))$. And the level of IL-10 was not affected by using insert plates in cocultured system in vitro (Figures $4(\mathrm{j})$ and $4(\mathrm{k})$ ), which indicated that IL-10 was the major functional cytokine of B10.

\section{Discussion}

The molecular mechanisms underlying B10-mediated immune suppression have been studied in various human and murine disease models, such as experimental autoimmune encephalomyelitis (EAE), inflammatory bowel disease (IBD), and rheumatoid arthritis (RA) [13, 39, 40]. Our previous study indicated that B10 could control lung inflammation through modulating Th balance in experimental silicosis in mice [31]. Here, we analyzed the regulatory effects of $\mathrm{B} 10$ on the Th responses by using the mouse primary B cell and Teff/Treg coculture system. Our results suggested a multiple capacity of B10 during the crystalline silica-induced inflammation in vitro. First, the insufficient B10 could promote the release of TNF- $\alpha$ and IL- 6 in the Teff and B cell coculture system in vitro. Second, the lack of B10 was able to directly elevate Th1/Th2/Th17 responses. Third, the deficient B10 could suppress the conversion of Teff into Treg. Fourth, the insufficient B10 was able to restrict the crystalline silica-induced Treg response, which was testified to contribute to the regulation of different Th type responses [28, 29]. This modulated function of B10 was not dependent on cell-cell contact, and in which IL-10 played a crucial role (Figure 5).

These findings, together with our previous study, provide an attractive explanation of how a very small population could maintain a balanced immune environment. In this study, the silica $\mathrm{B}+\mathrm{Teff}$ group failed to inhibit the secretion of inflammation cytokines compared with the control $\mathrm{B}+$ Teff group. It was tempting to speculate that using B cells instead of B10 cells might lead to the result. $\mathrm{B}$ cells exhibited a dual role in modulating immune response through either anti-inflammaton or proinflammation in both health and disease. $\mathrm{B}$ cells, identified by releasing IL-10, IL-35, and TGF- $\beta$, had been shown to limit inflammation, autoimmune disease, and tumor, while $\mathrm{B}$ cells, identified by secreting TNF- $\alpha$, IL-6, and GM-CSF, had been shown to promote disease $[14,41-44]$. So, the release of proinflammation cytokines of $\mathrm{B}$ cells might influence the results.

B10 cells were found at low frequencies (1-5\%) among spleen B cells in naïve mice but expanded in autoimmunity. They were also found in low numbers within blood, lymph nodes, Peyer's patches, intestinal tissues, and the CNS [20, 32, 45, 46]. It is impracticable to accumulate enough B10 for cell culture. Consequently, we used a B10 depletion strategy to explore its impact. Anti-CD22 mAb, 

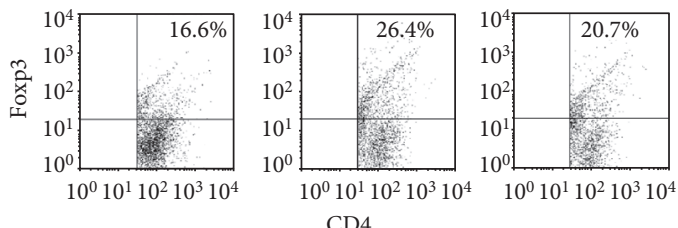

(a1)

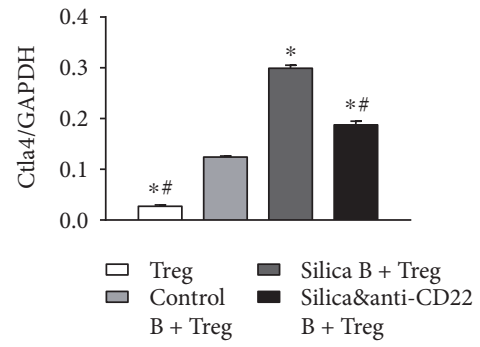

(c)
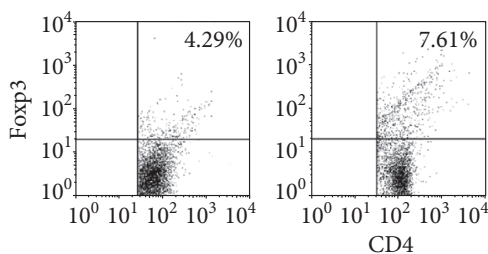

(f1)

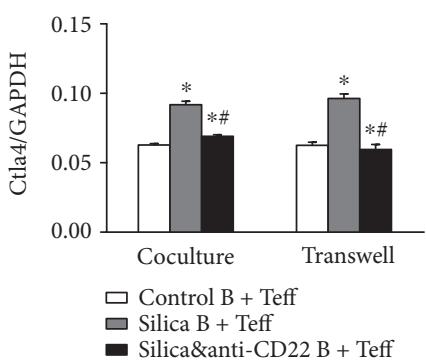

(h)

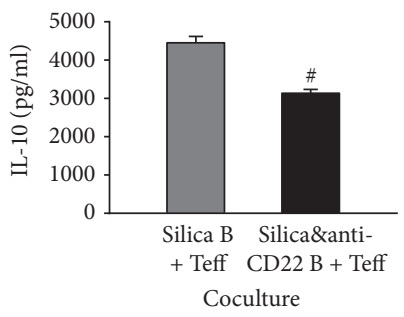

(k)

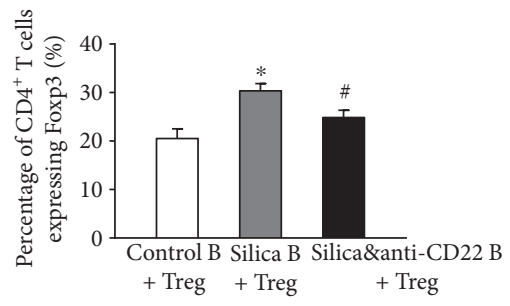

(a2)

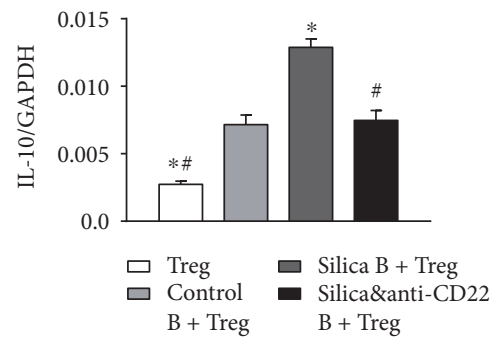

(d)

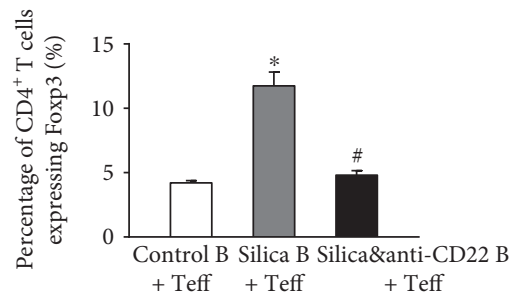

(f2)

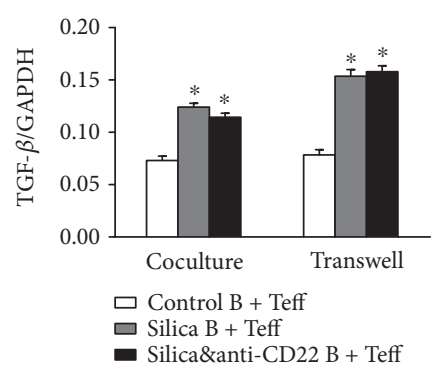

(i)

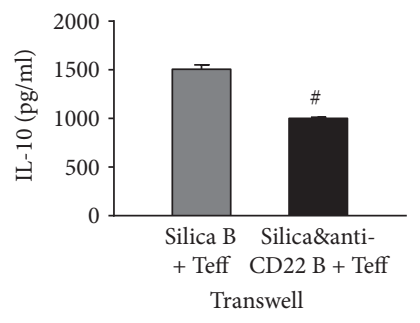

(l)

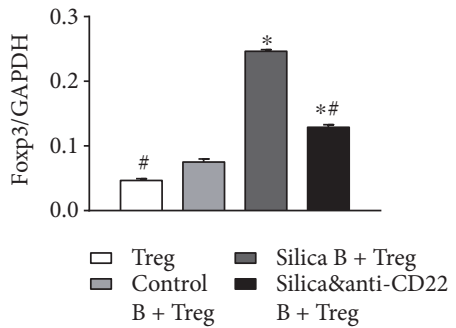

(b)

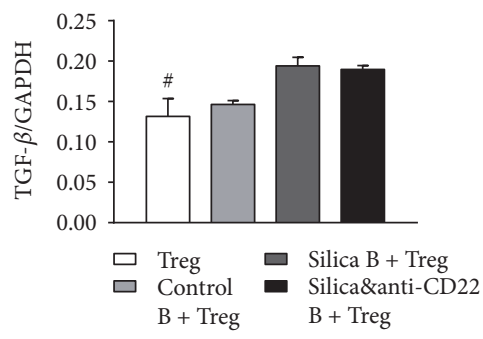

(e)

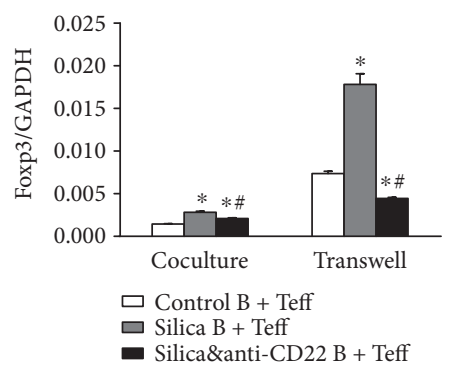

(g)

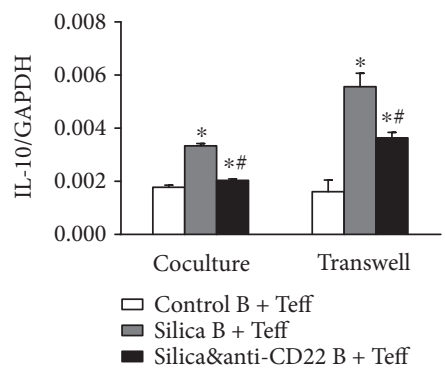

(j)

Figure 4: Insufficient B10 both suppressed Treg and inhibited the conversion of Teff into Treg. (a1, a2) The percentages of CD4 ${ }^{+} \mathrm{CD} 25^{+}$Treg in different groups of the B cell and Treg coculture system were studied by flow cytometry. (b-e) The expressions of Foxp3, CTLA4, IL-10, and TGF- $\beta$ in different groups of the $\mathrm{B}$ cell and Treg coculture system were assayed by real-time PCR. (f1, f2) The percentages of CD $4^{+} \mathrm{CD} 25^{+}$Treg in different groups of the B cell and Teff coculture system were studied by flow cytometry. (g-j) The expressions of Foxp3, CTLA4, IL-10, and TGF- $\beta$ in different groups of the B cell and Teff coculture system with or without insert plates were assayed by real-time PCR. (k, l) The secretions of IL-10 in supernatant of the B cell and Teff coculture system were assayed by CBA. (Data was presented as mean \pm SEM $(n=5)$. ${ }^{*} p<0.05$, significantly different compared with the control B + Teff group. ${ }^{*} p<0.05$, significantly different compared with the silica B + Teff group.) 


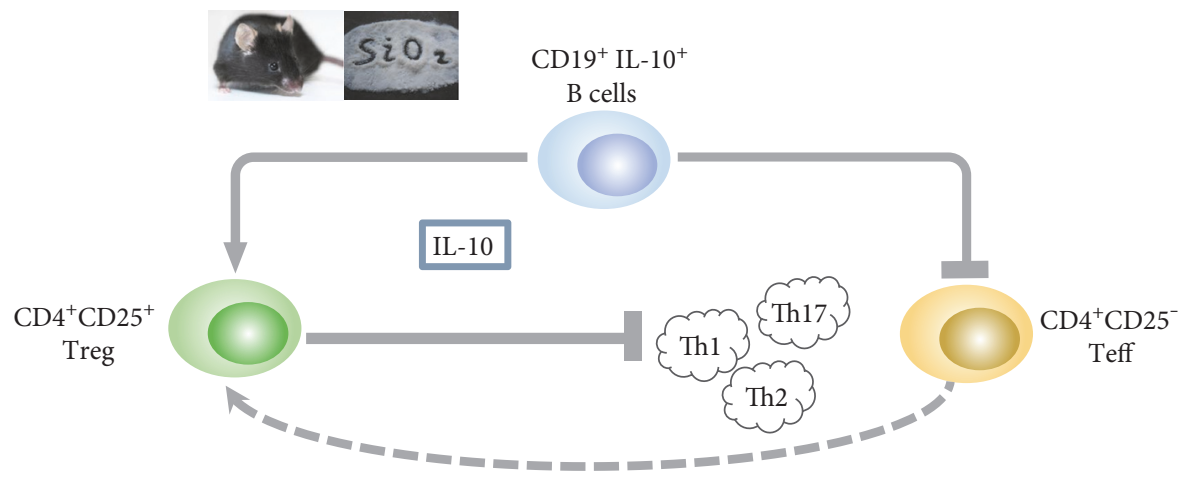

FIgURE 5: A schematic representation for the regulatory function of B10 on crystalline silica-induced Teff/Treg in vitro.

which was reported to eliminate B10 [31-33], was used to restrict the expansion of crystalline silica-induced $\mathrm{B} 10$. We found that the frequency of $\mathrm{CD} 19^{+} \mathrm{IL}-10^{+} \mathrm{B} 10$ in the silica\&anti-CD22 B cells group was much lower than the silica B cells counterparts, even after $72 \mathrm{~h}$ culture. This finding was consistent with our previous study; therefore, we used anti-CD22 mAb to investigate the regulatory effect of B10.

Several studies have demonstrated that B10 can inhibit Th1/Th2/Th17 responses and promote $\mathrm{CD} 4^{+} \mathrm{CD} 25^{-}$Teff converting into $\mathrm{CD} 4^{+} \mathrm{CD} 25^{+}$Treg in autoimmune diseases in vitro $[22,37,47]$. Our results confirmed the function of B10. However, in our previous study, we found that B10 inhibited Th1 responses only. Macrophage plays a crucial role in experimental silicosis $[1,7,48,49]$. Activation of alveolar macrophages can influence the lymphocytes by secreting cytokines, such as TNF- $\alpha$, IL- 6 , IL- $1 \beta$, and TGF- $\beta$. So, the Th2/Th17 cells might be partly affected by alveolar macrophages in vivo. Treg has diverse phenotypes, such as IL- $10^{+}$ Treg, TGF- $\beta^{+}$Treg, and IL- $35^{+}$Treg, according to the release of immunosuppressive cytokines [50-52]. In the current study, we found that $\mathrm{B} 10$ could convert $\mathrm{CD} 4^{+} \mathrm{CD} 25^{-}$Teff into Treg and increase the expression of Foxp 3 and CTLA4 as well as the release of IL-10. However, a B-1a cell subset was reported that could induce Foxp $3^{-} \mathrm{T}$ cells with regulatory activity which could produce high levels of IFN- $\gamma$ and IL-10, but minimal amounts of IL-4 [53]. IL-10 could convert $\mathrm{CD}^{+}{ }^{+} \mathrm{T}$ cells into Treg [54]. Our finding was consistent with the clinical study, which B10 could induce Foxp $3^{+} \mathrm{T}$ cells that could produce high levels of TGF- $\beta$ and IL-10 with regulatory activity [47].

In correlation with our original hypothesis, B10 could promote the activity of Treg. We cultured the $\mathrm{CD} 19^{+} \mathrm{B}$ cells from the different groups and $\mathrm{CD} 4^{+} \mathrm{CD} 25^{+}$Treg from the control group. Foxp 3 and CTLA4 have been identified as activated markers of Treg [50-52]. The percentage of $\mathrm{CD}^{+}{ }^{+}$Foxp $^{+}{ }^{+}$Treg and the expressions of CTLA4 and IL-10 increased obviously in the silica B + Treg group. Our findings were similar to the previous studies which detected the effect of B10 exerted on Treg [38, 47, 55, 56].

B10 might modulate Th responses through the direct contact between $\mathrm{B} 10$ and $\mathrm{CD}^{+} \mathrm{T}$ cells by costimulatory molecules, such as PD-L1, GITR, Tim-1, or CD86 [22, 38, $47,57,58]$. In the present study, a transwell was used to block the cell-cell contact in vitro. The results showed that the insufficient B10 led to the expansion of Th1/Th2/Th17 responses in cells both cocultured with and without a transwell. The regulatory effect of B10 by secreting IL-10 has been widely discussed $[12,23,59]$. In the current study, the level of IL-10 was much higher in the silica B + Teff group compared with that in the silica\&anti-CD22 B + Teff group. However, the level of TGF- $\beta$ was not significantly different between the silica B + Teff group and silica\&anti-CD22 B + Teff group. It is tempting to speculate that B10 might mainly suppress the Th responses by releasing IL-10 in experimental silicosis.

\section{Conclusions}

Taken together, our results demonstrated that B10 could suppress crystalline silica-activated proinflammatory cytokines in cocultured system in vitro. The proinhibitory function of B10 on Th responses was independent upon cell-cell contact. B10 could both affect Treg and promote the conversion of $\mathrm{CD} 4^{+} \mathrm{CD} 25^{-}$Teff into Treg, which could subsequently suppress the Th responses.

\section{Abbreviations}

IL-4: $\quad$ Interleukin 4

IL-13: Interleukin 13

IL-10: Interleukin 10

IL-6: $\quad$ Interleukin 6

IL-17A: Interleukin 17A

TNF- $\alpha$ : Tumor necrosis factor alpha

IFN- $\gamma$ : Interferon gamma

TGF- $\beta$ : $\quad$ Transforming growth factor beta

IL-23: Interleukin 23

Treg: $\quad$ Regulatory T cells

Teff: $\quad$ Effector $\mathrm{T}$ cells

T-bet: $\quad$ T cell-specific T-box transcription factor

GATA-3: GATA binding protein 3

Foxp3: $\quad$ Forkhead box P3

ROR- $\gamma$ t: RAR-related orphan receptor gamma

Th1: $\quad$ T helper type 1 cells

Th2: $\quad$ T helper type 2 cells

Th17: $\quad$ T helper type 17 cells

CD4: $\quad$ Cluster of differentiation 4 receptors

CD19: Cluster of differentiation 19 receptors

GAPDH: Glyceraldehyde-3-phosphate dehydrogenase. 


\section{Conflicts of Interest}

The authors declare no conflict of interest.

\section{Authors' Contributions}

Yiping Lu and Fangwei Liu contributed equally to this work.

\section{Acknowledgments}

This study was supported by the National Natural Science Foundation of China (no. 81273045) and the Program for Liaoning Innovative Research Team in University (LT2015028).

\section{References}

[1] S. R. Satpathy, V. R. Jala, S. R. Bodduluri et al., "Crystalline silica-induced leukotriene B4-dependent inflammation promotes lung tumour growth," Nature Communications, vol. 6, p. 7064, 2015.

[2] M. Lopes-Pacheco, E. Bandeira, and M. M. Morales, "Cell-based therapy for silicosis," Stem Cells International, vol. 2016, Article ID 5091838, 9 pages, 2016.

[3] H. L. Tan, M. Faisal, C. I. Soo, A. Y. Ban, R. A. Manap, and T. M. Hassan, "Dental technician pneumoconiosis mimicking pulmonary tuberculosis: a case report," BMC Pulmonary Medicine, vol. 16, p. 131, 2016.

[4] J. W. Lee, J. P. Myong, Y. J. Choi, S. Lee, B. S. Jo, and J. W. Koo, "Diagnosis of perinuclear anti-neutrophil cytoplasmic antibody-associated microscopic polyangiitis in silicotics: case report," Annals of Occupational and Environmental Medicine, vol. 28, p. 21, 2016.

[5] F. Huaux, "New developments in the understanding of immunology in silicosis," Current Opinion in Allergy and Clinical Immunology, vol. 7, no. 2, pp. 168-173, 2007.

[6] H. Takato, M. Yasui, Y. Ichikawa et al., "The specific chymase inhibitor TY-51469 suppresses the accumulation of neutrophils in the lung and reduces silica-induced pulmonary fibrosis in mice," Experimental Lung Research, vol. 37, pp. 101-108, 2011.

[7] C. C. Leung, I. T. S. Yu, and W. Chen, "Silicosis," The Lancet, vol. 379, pp. 2008-2018, 2012.

[8] K. M. Pollard, "Silica, silicosis, and autoimmunity," Frontiers in Immunology, vol. 7, p. 97, 2016.

[9] S. Chen, J. Yuan, S. Yao et al., "Lipopolysaccharides may aggravate apoptosis through accumulation of autophagosomes in alveolar macrophages of human silicosis," Autophagy, vol. 11, pp. 2346-2357, 2015.

[10] F. E. Lund and T. D. Randall, "Effector and regulatory B cells: modulators of CD4+ T cell immunity," Nature Reviews Immunology, vol. 10, pp. 236-247, 2010.

[11] S. Fillatreau, C. H. Sweenie, M. J. McGeachy, D. Gray, and S. M. Anderton, "B cells regulate autoimmunity by provision of IL-10," Nature Immunology, vol. 3, pp. 944-950, 2002.

[12] J. Han, L. Sun, X. Fan et al., "Role of regulatory b cells in neuroimmunologic disorders," Journal of Neuroscience Research, vol. 94, pp. 693-701, 2016.

[13] D. G. Adlowitz, J. Barnard, J. N. Biear et al., "Expansion of activated peripheral blood memory B cells in rheumatoid arthritis, impact of B cell depletion therapy, and biomarkers of response," PLoS One, vol. 10, article e0128269, 2015.
[14] R. Li, A. Rezk, Y. Miyazaki et al., "Proinflammatory GM-CSFproducing B cells in multiple sclerosis and B cell depletion therapy," Science Translational Medicine, vol. 7, no. 310, article 310ra166, 2015.

[15] I. Moreno Torres and A. Garcia-Merino, "Anti-CD20 monoclonal antibodies in multiple sclerosis," Expert Review of Neurotherapeutics, vol. 17, no. 4, pp. 359-371, 2017.

[16] X. Pan, Z. Ji, and J. Xue, "Percentage of peripheral CD19 $+\mathrm{CD} 24$ hiCD38hi regulatory B cells in neonatal sepsis patients and its functional implication," Medical Science Monitor, vol. 22, pp. 2374-2378, 2016.

[17] F. Figueiró, L. Muller, S. Funk, E. K. Jackson, A. M. O. Battastini, and T. L. Whiteside, "Phenotypic and functional characteristics of CD39high human regulatory B cells (Breg)," OncoImmunology, vol. 5, article e1082703, 2016.

[18] Y. Iwata, T. Matsushita, M. Horikawa et al., "Characterization of a rare IL-10-competent B-cell subset in humans that parallels mouse regulatory B10 cells," Blood, vol. 117, pp. 530-541, 2011.

[19] J. D. Bouaziz, H. Le Buanec, A. Saussine, A. Bensussan, and M. Bagot, "IL-10 producing regulatory B cells in mice and humans: state of the art," Current Molecular Medicine, vol. 12, pp. 519-527, 2012.

[20] T. F. Tedder, "B10 cells: a functionally defined regulatory B cell subset," The Journal of Immunology, vol. 194, pp. 1395-1401, 2015.

[21] E. C. Rosser and C. Mauri, "Regulatory B cells: origin, phenotype, and function," Immunity, vol. 42, pp. 607-612, 2015.

[22] A. R. Khan, E. Hams, A. Floudas, T. Sparwasser, C. T. Weaver, and P. G. Fallon, "PD-L1hi B cells are critical regulators of humoral immunity," Nature Communications, vol. 6, p. 5997, 2015.

[23] J. Durand and E. Chiffoleau, "B cells with regulatory properties in transplantation tolerance," World Journal of Transplantation, vol. 5, pp. 196-208, 2015.

[24] X. Zhou, Y. X. Su, X. M. Lao, Y. J. Liang, and G. Q. Liao, "CD19(+)IL-10(+) regulatory B cells affect survival of tongue squamous cell carcinoma patients and induce resting CD4 $(+)$ T cells to CD4(+)Foxp3(+) regulatory T cells," Oral Oncology, vol. 53, pp. 27-35, 2016.

[25] Y. Chen, C. Li, D. Weng et al., "Neutralization of interleukin17A delays progression of silica-induced lung inflammation and fibrosis in C57BL/6 mice," Toxicology and Applied Pharmacology, vol. 275, pp. 62-72, 2014.

[26] L. Song, D. Weng, W. Dai et al., "Th17 can regulate silicainduced lung inflammation through an IL-1beta-dependent mechanism," Journal of Cellular and Molecular Medicine, vol. 18, pp. 1773-1784, 2014.

[27] W. Tang, F. Liu, Y. Chen et al., "Reduction of IL-17A might suppress the Th1 response and promote the Th2 response by boosting the function of Treg cells during silica-induced inflammatory response in vitro," Mediators of Inflammation, vol. 2014, Article ID 570894, 11 pages, 2014.

[28] F. Liu, J. Liu, D. Weng et al., "CD4+CD25+Foxp3+ regulatory $\mathrm{T}$ cells depletion may attenuate the development of silicainduced lung fibrosis in mice," PLoS One, vol. 5, article e15404, 2010.

[29] L. Song, D. Weng, F. Liu et al., "Tregs promote the differentiation of Th17 cells in silica-induced lung fibrosis in mice," PloS One, vol. 7, article e37286, 2012.

[30] H. Hayashi, Y. Miura, M. Maeda et al., "Reductive alteration of the regulatory function of the CD4(+)CD25(+) T cell fraction 
in silicosis patients," International Journal of Immunopathology and Pharmacology, vol. 23, no. 4, pp. 1099-1109, 2010.

[31] F. Liu, W. Dai, C. Li et al., "Role of IL-10-producing regulatory $\mathrm{B}$ cells in modulating T-helper cell immune responses during silica-induced lung inflammation and fibrosis," Scientific Reports, vol. 6, article 28911, 2016.

[32] T. Matsushita, M. Horikawa, Y. Iwata, and T. F. Tedder, "Regulatory B cells (B10 cells) and regulatory T cells have independent roles in controlling experimental autoimmune encephalomyelitis initiation and late-phase immunopathogenesis," Journal of Immunology, vol. 185, pp. 2240-2252, 2010.

[33] K. M. Haas, S. Sen, I. G. Sanford, A. S. Miller, J. C. Poe, and T. F. Tedder, "CD22 ligand binding regulates normal and malignant B lymphocyte survival in vivo," The Journal of Immunology, vol. 177, pp. 3063-3073, 2006.

[34] L. Zhou, M. M. Chong, and D. R. Littman, "Plasticity of CD4+ T cell lineage differentiation," Immunity, vol. 30, pp. 646-655, 2009.

[35] D. S. Robinson and A. O'Garra, "Further checkpoints in Th1 development," Immunity, vol. 16, pp. 755-758, 2002.

[36] J. Zhu, H. Yamane, J. Cote-Sierra, L. Guo, and W. E. Paul, "GATA-3 promotes Th2 responses through three different mechanisms: induction of Th2 cytokine production, selective growth of Th2 cells and inhibition of Th1 cell-specific factors," Cell Research, vol. 16, pp. 3-10, 2006.

[37] F. Flores-Borja, A. Bosma, D. $\mathrm{Ng}$ et al., "CD19 +CD24hiCD38hi B cells maintain regulatory T cells while limiting TH1 and TH17 differentiation," Science Translational Medicine, vol. 5, no. 173, article 173ra23, 2013.

[38] A. Kessel, T. Haj, R. Peri et al., "Human CD19(+)CD25(high) $B$ regulatory cells suppress proliferation of CD4(+) T cells and enhance Foxp3 and CTLA-4 expression in T-regulatory cells," Autoimmunity Reviews, vol. 11, pp. 670-677, 2012.

[39] M. M. Ansary, S. Ishihara, A. Oka et al., "Apoptotic cells ameliorate chronic intestinal inflammation by enhancing regulatory B-cell function," Inflammatory Bowel Diseases, vol. 20, pp. 2308-2320, 2014.

[40] A. Ray, S. Basu, C. B. Williams, N. H. Salzman, and B. N. Dittel, "A novel IL-10-independent regulatory role for B cells in suppressing autoimmunity by maintenance of regulatory T cells via GITR ligand," The Journal of Immunology, vol. 188, pp. 3188-3198, 2012.

[41] C. Mauri and A. Bosma, "Immune regulatory function of B cells," Annual Review of Immunology, vol. 30, pp. 221241, 2012.

[42] T. F. Tedder and W. J. Leonard, "Autoimmunity: regulatory B cells-IL-35 and IL-21 regulate the regulators," Nature Reviews Rheumatology, vol. 10, pp. 452-453, 2014.

[43] P. J. Rauch, A. Chudnovskiy, C. S. Robbins et al., "Innate response activator B cells protect against microbial sepsis," Science, vol. 335, no. 6068, pp. 597-601, 2012.

[44] V. D. Dang, E. Hilgenberg, S. Ries, P. Shen, and S. Fillatreau, "From the regulatory functions of B cells to the identification of cytokine-producing plasma cell subsets," Current Opinion in Immunology, vol. 28, pp. 77-83, 2014.

[45] K. Yanaba, J. D. Bouaziz, T. Matsushita, T. Tsubata, and T. F. Tedder, "The development and function of regulatory B cells expressing IL-10 (B10 cells) requires antigen receptor diversity and TLR signals," Journal of Immunology, vol. 182, pp. 7459-7472, 2009.
[46] D. Maseda, K. M. Candando, S. H. Smith et al., "Peritoneal cavity regulatory B cells (B10 cells) modulate IFN-gamma +CD4+ T cell numbers during colitis development in mice," Journal of Immunology, vol. 191, pp. 2780-2795, 2013.

[47] Y. Liu, L. Cheng, S. Wu et al., "IL-10-producing regulatory B-cells suppressed effector T-cells but enhanced regulatory T-cells in chronic HBV infection," Clinical Science, vol. 130, pp. 907-919, 2016.

[48] M. Sayan and B. T. Mossman, "The NLRP3 inflammasome in pathogenic particle and fibre-associated lung inflammation and diseases," Particle and Fibre Toxicology, vol. 13, p. 51, 2016.

[49] S. E. Mischler, E. G. Cauda, M. Di Giuseppe et al., "Differential activation of RAW 264.7 macrophages by size-segregated crystalline silica," Journal of Occupational Medicine and Toxicology, vol. 11, p. 57, 2016.

[50] J. Abramson and E. S. Husebye, "Autoimmune regulator and self-tolerance-molecular and clinical aspects," Immunological Reviews, vol. 271, no. 1, pp. 127-140, 2016.

[51] M. O. Li and A. Y. Rudensky, "T cell receptor signalling in the control of regulatory $\mathrm{T}$ cell differentiation and function," Nature Reviews Immunology, vol. 16, pp. 220-233, 2016.

[52] A. Tanaka and S. Sakaguchi, "Regulatory T cells in cancer immunotherapy," Cell Research, vol. 27, pp. 109-118, 2016.

[53] L. H. Hsu, K. P. Li, K. H. Chu, and B. L. Chiang, “A B-1a cell subset induces Foxp3(-) T cells with regulatory activity through an IL-10-independent pathway," Cellular \& Molecular Immunology, vol. 12, pp. 354-365, 2015.

[54] G. Noh and J. H. Lee, "Regulatory B cells and allergic diseases," Allergy, Asthma \& Immunology Research, vol. 3, pp. 168-177, 2011.

[55] T. Adjobimey, J. Satoguina, J. Oldenburg, A. Hoerauf, and L. E. Layland, "Co-activation through TLR4 and TLR9 but not TLR2 skews Treg-mediated modulation of Igs and induces IL-17 secretion in Treg: B cell co-cultures," Innate Immunity, vol. 20, pp. 12-23, 2014.

[56] F. T. Lu, W. Yang, Y. H. Wang et al., “Thymic B cells promote thymus-derived regulatory $\mathrm{T}$ cell development and proliferation," Journal of Autoimmunity, vol. 61, pp. 62-72, 2015.

[57] P. A. Blair, L. Y. Norena, F. Flores-Borja et al., "CD19(+)CD24(hi)CD38(hi) B cells exhibit regulatory capacity in healthy individuals but are functionally impaired in systemic lupus erythematosus patients," Immunity, vol. 32, pp. 129-140, 2010.

[58] A. Das, G. Ellis, C. Pallant et al., "IL-10-producing regulatory B cells in the pathogenesis of chronic hepatitis B virus infection," The Journal of Immunology, vol. 189, pp. 3925-3935, 2012.

[59] H. Rincon-Arevalo, C. C. Sanchez-Parra, D. Castano, L. Yassin, and G. Vasquez, "Regulatory B cells and mechanisms," International Reviews of Immunology, vol. 35, pp. 156-176, 2016. 


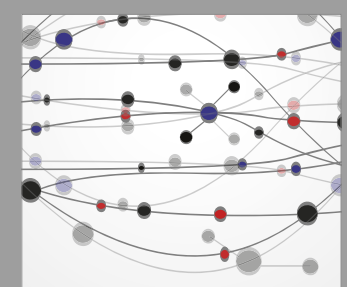

The Scientific World Journal
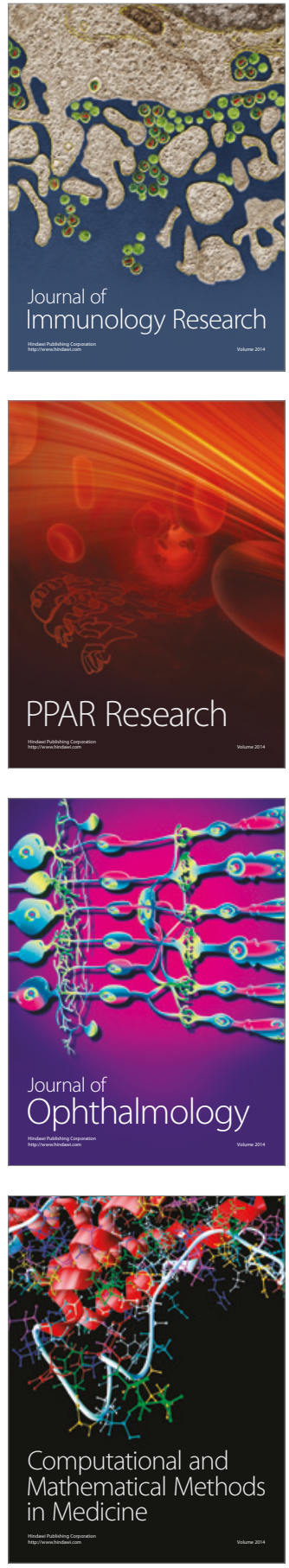

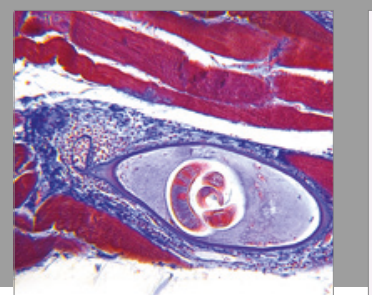

Gastroenterology Research and Practice
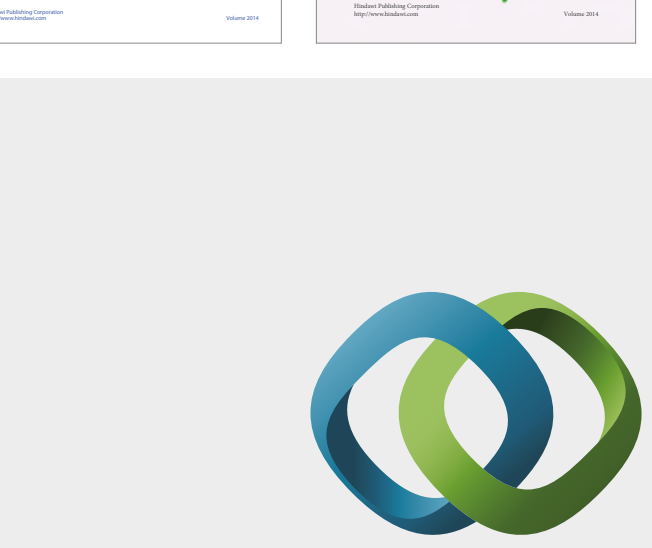

\section{Hindawi}

Submit your manuscripts at

https://www.hindawi.com
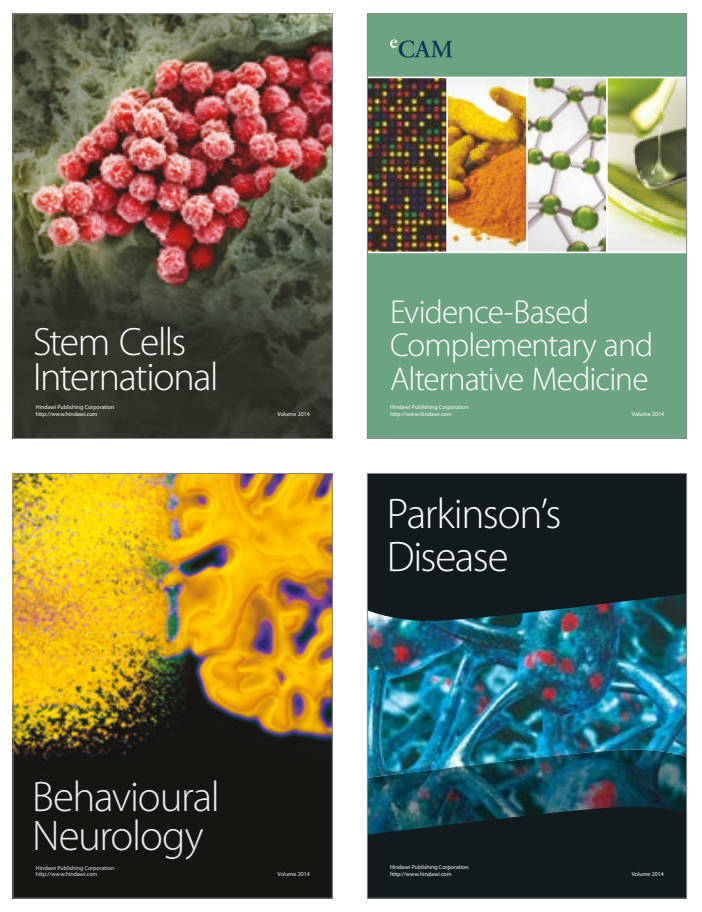
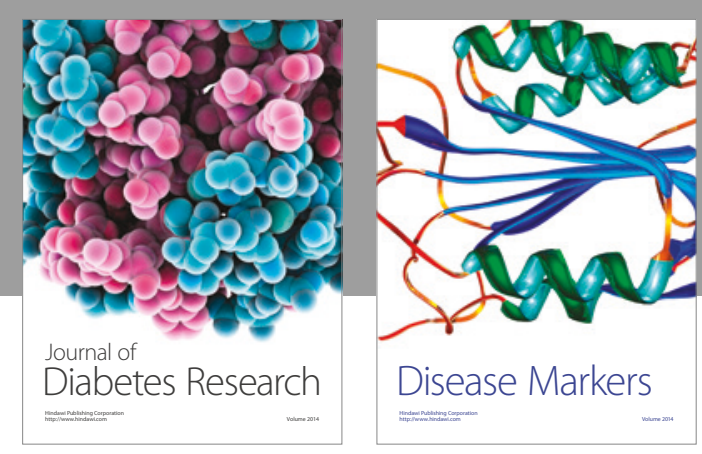

Disease Markers
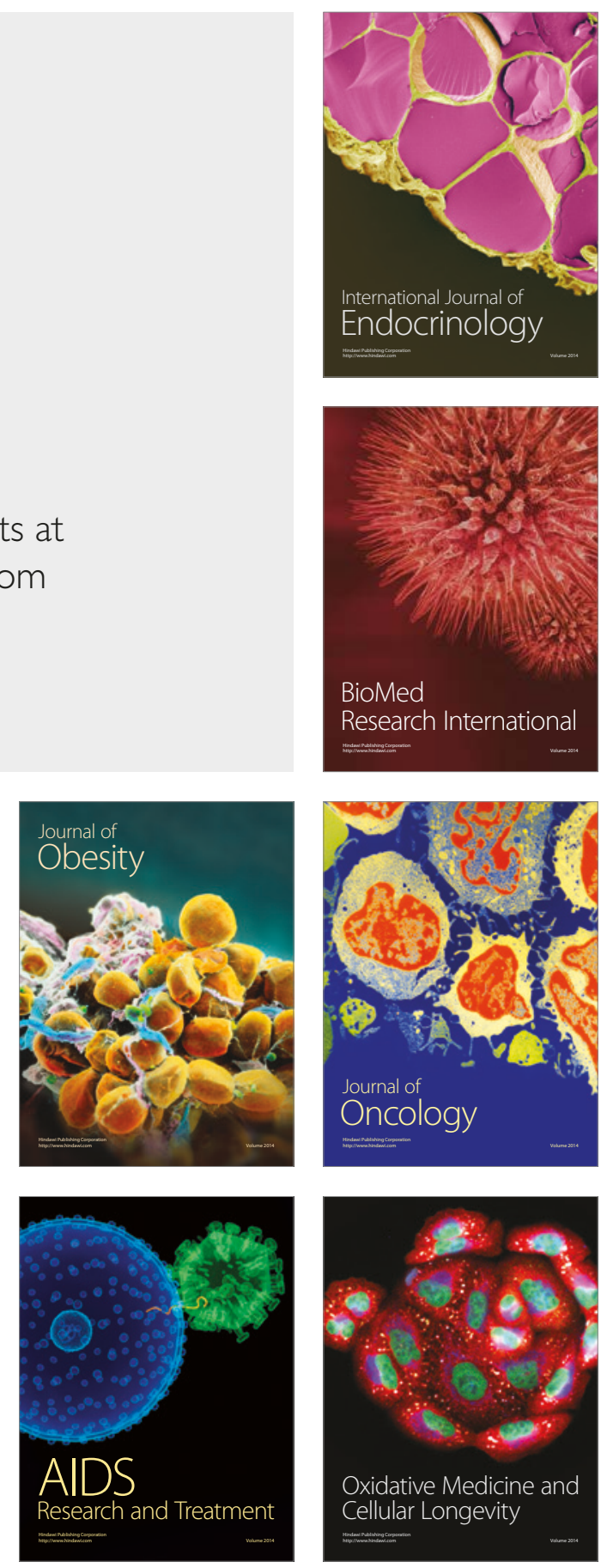